\title{
Support teachers' beliefs about the academic achievement of students with special educational needs
}

\author{
José Castro Silva and José Morgado
}

\begin{abstract}
José Castro Silva, lecturer in sciences of education, and José Morgado, assistant professor, both work at the Instituto Superior de Psicologica Aplicada in Lisboa, Portugal. In this article, they describe their study of support teachers' beliefs about the academic achievement of school students with special educational needs. The 'support teachers' who were the subject of this study work in mainstream schools where the majority of pupils with special educational needs are educated in mainstream classes run by 'general teachers'. The work of the support teachers is supervised and supported by 'special education team co-ordinators'. The study reported here set out to elicit the support teachers' beliefs about the factors that contribute to success at school for pupils with special educational needs. Results suggest that the support teachers consider that factors including 'school climate', 'curriculum design' and 'teaching approach' contribute significantly to achievements among these pupils. On the other hand, analysis reveals that the support teachers attribute difficulties and lack of achievement significantly to 'out-of-school' contextual variables. These findings are related to a detailed review of the literature and the authors discuss the implications for policy, practice and professional development.
\end{abstract}

Key words: support teachers, beliefs, academic achievement, pupils, special educational needs.

The determinants and consequences of teachers' beliefs Researchers in the social cognition field have suggested that teachers' beliefs about, and attitudes toward, student diversity and heterogeneity play a central role in students' integration into standard settings (Semmel, Abernathy, Butera \& Lesar, 1991). In particular, empirical data show that teachers possess low academic expectations in relation to children with special educational needs. In a study by Aloia, Maxwell and Aloia (1981), teachers' impressions of the intellectual potential of a child who was labelled as 'mentally retarded' were lower than those for a non-disabled child.

What is more, early studies on educational integration (for example, Jamieson, 1984) found that teachers were very apprehensive about the quality of the academic work that children with special educational needs would produce once they were integrated in regular classrooms. They also expressed other doubts, namely concerns about the degree to which children were prepared for integration and the amount of individualised education time that would be required by pupils with special learning needs (Bender, Vail \& Scott, 1995).

Despite the general acceptance of the principle of integration, some studies reveal that teachers do not seem ready for it (Semmel et al., 1991). This scenario is also supported in Scruggs and Mastropieri's (1996) review of studies conducted between 1956 and 1995, which concluded that about $70 \%$ of teachers support the concept of mainstreaming, but that only a third feel that they have sufficient time, skills, training or resources to support the practice of integration.

In overall terms, teachers' attitudes toward integration are determined by several factors. The first of these is training. Bender et al. (1995) showed that teachers' attitudes toward school integration did positively correlate with the number of in-service training courses on teaching children with special educational needs that they had taken. According to these data, teachers working at higher grade-levels displayed more negative attitudes. Experience is a second factor. Data from a study by Center and Ward (1987) showed that younger teachers - and consequently those with less teaching experience - displayed more favourable attitudes toward mainstreaming. Chalmers (1991) showed that elementary and secondary teachers tend to differ in both their views of integration and the kinds of classroom accommodations they make for students who experience special educational needs. Villa, Thousand, Meyers and Nevin's (1996) research on the perceptions of teachers and administrators working in heterogeneous education environments suggest that experience with the practice of inclusive education develops teachers' ability, their perception of competence and their belief in educating heterogeneous classes. What is more, findings from a study by Soodak, Podell and Lehman (1998) indicate that teachers who possessed low teaching efficacy; who lacked teaching experience; or who had not frequently employed differentiated teaching practices were found to be less receptive to integration.

Along with their attitudes, teachers' attribution patterns offer a useful framework for understanding teachers' beliefs about the academic success and failure of students with 
special educational needs in the classroom. According to researchers in the attribution field (Cooper \& Burger, 1980), negative or unexpected outcomes on the part of students commonly result from teachers' attribution patterns. Of the most common of these patterns, pupils' ability in an academic context (that is, aptitudes and learnt skills) and effort expended are the main perceived causes of individual success or failure in academic settings (Graham, 1991). Studies that look at teachers' expectations and consequent behaviour have demonstrated that students' academic performance can be affected by the ways in which they are treated by teachers and by the latter's attitudes (see Good, 1981). For example, failure due to causes that teachers perceive as fixed, such as low levels of ability, may result in a high level of expectation that failure will occur, whereas failure due to unstable causes, such as a teacher's instructional methods, may lead to a high expectation that something can be done to modify the students' academic performance. Olson, Chalmers and Hoover (1997) found that the individualisation of expectations was a requisite for effective integrated services and that, when interviewed, teachers emphasised the need to set those expectations at a level that would produce achievement. In related research, Rolinson and Medway (1985) found some evidence that teachers are more likely to attribute success among children with special educational needs to their own efforts than to those of the children, whereas they attribute children's academic failures to the children rather than to themselves.

\section{Factors that contribute to academic achievement}

Besides teachers' attitudes, other factors that affect the academic success of students with special educational needs include:

- teachers' reluctance to change their culture and teaching practices (Fullan \& Miles, 1992), including fears and anxieties associated with change, the practicality of change, perceived school support and personal costs and efforts (Welch, 1989);

- the availability of technical assistance (Kauffman, Lloyd \& McGee, 1989);

- teachers' knowledge about students' traits, characteristics and educational needs (Semmel et al., 1991);

- the use of co-operative learning structures (Johnson \& Johnson, 1994);

- the development of working relationships between teachers (Pugach \& Johnson, 1994);

- curricular innovations and new instructional approaches (Nevin, 1993; Udvari-Solner \& Thousand, 1995).

Literature on factors that contribute to school quality also suggests that changes in student performance and school quality are related to a set of proximal variables, such as educational strategies and practices, as well as to distal variables, when school reorganisation and educational polices play an important role (Wang, Haertl \& Walberg, 1993). According to results that are highlighted in the Wang et al. study, the quality of the diagnosis of learning problems could improve if attention were paid to a set of variables that include information about students' capacities and aptitudes; contextual factors such as family involvement in activities undertaken at school; and the quality of teacher-student interactions, among others.

Finally, the literature on school effectiveness has identified several forms of teacher behaviour that are strongly associated with the academic achievement of children with special educational needs (for example, Berliner, 1985). These include:

- allocating sufficient time to the direct teaching of basic skills;

- conducting lessons in such a way that students maintain a high rate of task involvement;

- defining both teaching goals and objectives and expected pupil outcomes;

- designing instruction so that students enjoy both the possibility of experiencing successful task resolution and greater levels of satisfaction and motivation;

- the availability of a variety of learning models that enable teachers to present problems as tasks to be solved and encourage students to understand and explain their thinking (Englert, Tarrant \& Mariage, 1992).

Working on the basis that beliefs guide behaviour and, as such, influence teacher-student academic interactions, the purpose of the present study was to identify and characterise teachers' beliefs about the variables that affect the academic achievement of students with special educational needs. We suggest that teachers' concerns and beliefs may determine the pedagogical methods that are employed in classrooms serving students with special educational needs.

\section{Method}

\section{Context}

In the schools in which this research was carried out, the majority of students with special educational needs are fully educated in mainstream classes run by 'general teachers'. Under exceptional circumstances, some students are withdrawn in order to receive specialist support and input. 'Support teachers' work with the senior managers and general teachers in schools in order to:

- identify and assess students' special educational needs;

- train and support the general teachers through co-teaching and co-operative work on curriculum design and adaptation;

- directly support students with special educational needs.

The support teachers work in teams, based outside the schools. Their work is supervised and supported by 'special education team co-ordinators' who are experienced teachers with specialist training. A specialist qualification is not required in order to work as a support teacher. In fact, $70 \%$ of support teachers do not have specialist training in teaching pupils with special educational needs.

\section{Participants}

The respondents were 76 support teachers working in six special educational teams in Lisbon, Portugal. Ninety-three percent of the respondents were female. The group's mean 
age was 43 years (range 32-60). Participants possessed 20 and 12 years' mean experience as general and support teachers respectively. Of the total sample, $63 \%$ had attended special education training.

\section{Instrument}

A survey was undertaken with a view to gathering information from respondents on the causes of achievement and academic failure among students with special educational needs. The survey consisted of three sections. The first section of the protocol included two open questions that had been drawn up in such a way as to help the teachers describe their perceptions of their students' academic experiences. In the first open question, we asked teachers to indicate factors that in their opinion contribute to the educational success of students with special educational needs. The second question invited participants to mention factors that influence educational failure among students with special educational needs. The main goal of the second section was to assess five factors which Wang et al. (1993) suggested contribute to academic success, that is: teaching approach, school climate, curriculum design, student and out-of-school context. In this section, responses were designed to be recorded on a five-point Likert-type scale $(1=$ totally disagree, $2=$ disagree, $3=$ undecided, $4=$ agree and $5=$ totally agree). Section three asked for biographical details concerning gender, age, overall teaching experience, teaching experience with students with special educational needs and special education expertise. This article provides data that were obtained in the first section.

\section{Procedure}

We asked the special education team co-ordinators to give support teachers a pack containing the survey instrument, some general instructions and recommendations on how to return the survey. The instrument was coded to protect the respondents' identities. Of the 135 surveys delivered, we collected 76 completed surveys $(56.3 \%)$.

\section{Data analysis}

The questions that guided our examination of the survey data were as follows:

1. What factors contribute to the academic achievement of students with special educational needs?

2. What factors contribute to the academic failure of students with special educational needs?

Teacher beliefs that seemed relevant to these research questions were interpreted in the light of five general themes:

- teaching approach, which involves variables such as instructional approaches used; classroom resource management; student progress monitoring; quality and amount of education delivered; the use of devices to monitor students' progress; the establishment of classroom routines; and teacher-student interactions (Wang et al., 1993);
- school climate, which covers aspects concerning schools' ecological features, including the characteristics of their physical environment; milieu variables focusing on the characteristics of persons and groups within the school environment; social system variables; including the patterns of interactions and relationships within a school; and culture variables including the values and beliefs of the various groups within a school (Anderson, 1985);

- curriculum design, which consists of a set of variables such as the delivery of instructional materials and their organisation and disposal, and also includes the strategies set out in the curriculum and the instruction materials (Wang et al., 1993);

- $\quad$ student characteristics, including issues concerning students' academic and social characteristics, with particular emphasis on aspects such as retention or placement in special education structures, psychological aptitudes and affective variables (Wang et al., 1993);

- out-of-school contextual variables, which covers variables that are related to family environment, such as parental activities and attitudes that support children's learning; parental expressions of interest that are reflected in children's school work; participation in school meetings; parental expectations about educational success; and parental accompaniment and supervision of students' learning activities.

The researcher defined a number of categories and subcategories and then coded the data accordingly. Interrater reliability was checked by having three judges independently assign each data unit. The agreement rate was calculated by dividing the sum of the agreements and disagreements and multiplying by 100 . The resulting calculations showed that interrater reliability ranged between $87 \%$ and $95 \%$.

Content analysis techniques, such as text encoding, category counts, the development of key-word-in-context and word-frequency lists described by Weber (1990) and others (for example, Bogdan \& Biklen, 1983) were employed. A category system was developed and used to classify qualitative data while preserving the coherence and richness of the subject material.

\section{Findings}

Each of the themes and categories is summarised and relevant statements are reproduced below. The context of each theme is mentioned and commented upon and the categories and subcategories are used to illustrate and help to interpret the responses given by teachers.

\section{Support teachers' beliefs about the factors that contribute to the academic achievements of students with special educational needs \\ Teaching approach \\ Table 1 shows the categories that contribute to the "teaching approach' theme, which encompasses eight categories.}


'Teaching approach' figures as the main factor and is mentioned by one-third (37\%) of support teachers.

Table 1: Percentage of categories incorporating the theme 'teaching approach'

\begin{tabular}{|ll|r|}
\hline Theme & Category & Percentage \\
\hline & Teacher-student interactions & 10.5 \\
& Teachers' expectations & 8.8 \\
Teaching & Specialised techniques & 5.5 \\
approach & Teaching rhythm & 3.3 \\
& Feedback & 3.3 \\
& Flexibility of strategies & 2.8 \\
& Individualised teaching & 1.6 \\
& Skills development & 37.0 \\
\hline
\end{tabular}

Let us start by looking at teacher behaviour. The data indicate that a good, empathy-based relationship between teacher and student is perceived as a contributory factor in the pupils' academic success of students with special educational needs, indicating that teacher-student interactions are a core element in determining a positive learning and teaching relationship.

In addition to social interactions between students and educators, the process of setting adjusted expectations for the academic outcomes of integrated students also appears as a crucial factor. In the opinion of teachers, 'believing in students' capacities' makes a major contribution to their academic success.

Unlike the two previous categories, which are clearly based on social interactions in a classroom context, the remaining ones stressed:

- the importance of using differentiated instructional devices - for example, the availability of peer tutoring assistance, or arranging activities and materials that improve student achievement;

- the development of management techniques through which to heighten pupil engagement when performing assigned tasks and the use of reinforcement techniques;

- the extent to which teachers can manage their teaching rhythm so that pupils are able to follow the lesson, bearing in mind their learning styles and limitations;

- the use of adaptive, individualised and flexible instruction methods that foster skills development, and the mobilisation of instructional strategies that respect both students' educational needs and any prior diagnostic information.

School climate

Table 2 shows the four categories that contribute to the 'school climate' theme.
Table 2: Percentage of categories incorporating the theme 'school climate'

\begin{tabular}{|ll|r|}
\hline Theme & Category & Percentage \\
\hline & Teacher collaboration & 12.0 \\
School & School attendance & 4.4 \\
climate & Resources & 3.8 \\
& Teaching training & 1.1 \\
\hline & & Subtotal \\
\end{tabular}

'School climate' comes second only to 'teaching approach' and is referred to by $21.3 \%$ of support teachers. Co-operation between all of the educational support services and families is seen as a factor that is crucial to students' academic achievement. In addition, teacher collaboration networks; school attendance conditions and resources (human and material); teacher training programmes that address the impacts of scholastic integration; and attitudes towards students with special needs also emerge as key elements in the success that students with special educational needs achieve in regular learning contexts.

Curriculum design

Table 3 shows the two categories that contribute to the 'curriculum design' theme.

Table 3: Percentage of categories incorporating the theme 'curriculum design'

\begin{tabular}{|ll|r|}
\hline Theme & Category & Percentage \\
\hline Curriculum & Programme design & 16.1 \\
design & Curriculum adaptation & 4.4 \\
\hline & & Subtotal \\
\hline
\end{tabular}

The third theme was evoked by $20.5 \%$ of the respondent support teachers. When asked about curriculum design, teachers stressed both the importance of programme design - especially curricular schedules which involve pedagogical resources that are adaptable to students' educational needs - and arranging activities and materials in accordance with students' interests.

\section{Student characteristics}

Table 4 shows the three categories that contribute to the 'student characteristics' theme.

Table 4: Percentage of categories incorporating the theme 'student characteristics'

\begin{tabular}{|ll|c|}
\hline Theme & Category & Percentage \\
\hline & Prior assessment & 5.5 \\
Student & Academic motivation & 3.3 \\
characteristics & Affective factors & 2.2 \\
\hline & & Subtotal \\
& & 11.0 \\
\hline
\end{tabular}

'Student characteristics' is the fourth factor and was evoked by $11 \%$ of support teachers. Student variables that 
contribute to their educational success include valuable information about educational support provided; intervention strategies; students' existing knowledge; students' degree of investment and responsibility; and lastly, affective factors that influence and determine learning motivation.

Out-of-school context

Table 5 shows the three categories that contribute to the 'out-of-school context' theme.

Table 5: Percentage of categories incorporating the theme 'out-of-school context'

\begin{tabular}{|ll|c|}
\hline Theme & Category & Percentage \\
\hline Out-of- & Parental involvement & 5.0 \\
school & Family climate & 2.7 \\
context & Attitudes change & 1.1 \\
\hline & & Subtotal \\
\hline
\end{tabular}

'Out-of-school context' is the last and least common factor mentioned by support teachers. It was only cited by $8.8 \%$ of the respondents but, in their opinion, family involvement and participation in decision-making about curriculum planning; support in instructional options in the classroom; and a positive family climate favouring student learning all play an important role in learning at school.

Teachers also reported the need to alter community attitudes in such a way as to achieve greater acceptance of students with special educational needs in general education settings.

\section{Discussion}

Variables that influence the academic achievement and failure of students with special educational needs, as perceived by support teachers

This study sought to analyse and characterise the nature of support teachers' beliefs about the elements that play a part in determining the academic achievement of students with special educational needs. In line with previous work in the field of school learning variables (for example, Wang et al., 1993 ) and research on patterns of teacher attributions of the causes of pupils' academic success (for example, Cooper $\&$ Burger, 1980), the results show that the identification and characterisation of teachers' beliefs may constitute a primary step towards changing actual pedagogical methods. Corroborating the results of earlier research, it would seem that instructional practices are perceived by teachers to be a key ingredient in the academic performance of students with special educational needs in a scholastic context. According to interviewees, substantive instructional adaptations are essential in order to respond successfully to pupils. This view of teaching styles is consistent with the majority of instructional strategies that are emerging in the literature on teaching diverse communities of learners (Skrtic, Sailor \& Gee, 1996). Far more than basic numeracy, literacy and functional skills, teachers emphasised the need to implement a set of adaptive teaching approaches including:
1. modification of instruction (for example, demonstration of new skills and materials, monitoring pupils' understanding);

2. modification of assignments (for example, dividing tasks into small steps, lowering difficulty levels);

3. modification of instructional materials (providing alternative materials or supplementary aids);

4. modification of curriculum content (reducing programme content difficulty);

5. enhancing students' efforts and gains (praising and encouraging);

6. diversifying evaluation devices (using diverse measures to access academic difficulties and progress).

In principle, proposals of this kind reveal the depth to which teachers are familiar with educational strategies that have been put forward in the past two decades as a result of the pressure that the regular education initiative (for example, Gartner \& Lipsky, 1987) and the inclusive education movement (for example, Booth, Ainscow \& Dyson, 1997) have exerted in their advocacy of educating all learners in general education classrooms. Still, when it comes to instructional practices as a whole, teachers' expectations are of particular relevance to effective teaching. This result is consistent with other research conducted in schools and provides further evidence of the importance of adjusting expectations in relation to pupils' academic performance (Reynolds, 1990). Similarly, it is important to emphasise the teacher-student relationship, both social and academic. As in previous studies (for example, Wang et al., 1993), this category plays a central role in explaining variables which help to ensure the use of effective instructional practices.

Where the second theme raised by the survey data - 'school climate' - is concerned, we will focus our discussion on teacher collaboration. Confirming previous studies in the area of collaboration initiatives among educational staff (for example, Rainforth \& England, 1997), teachers emphasised the development of collaborative relationships between general classroom and support personnel as a predictor of the academic success of students with special educational needs. Equally relevant to the school attainment of students with special educational needs are both school community efforts designed to eliminate physical barriers and the adequacy of the material conditions required to foster students' full scholastic integration. Teachers also highlighted the role of school leadership in the promotion of training programmes covering specific instructional needs related to the promotion of students' participation in classroom activities. Finally, teachers picked out resource management - namely using resources in a flexible manner that enables teachers to access them easily when needed. In parallel to these attribution patterns, Slee (1990) and Ainscow (1997) underlined teachers' professional development as a feature that is crucial to school effectiveness. According to Ainscow (1997), schools should organise training courses to help teachers improve both their attitudes and their teaching strategies. 
The third theme on which teachers focused is "curriculum design'. Several noted that the curricular adaptation decision-making process acts as a catalyst for them to reflect on instructional planning. Teachers are of the opinion that attempts to include students in classroom routines require innovative teaching approaches and those teachers who wish to question their planning methodology should ask themselves: What is the subject? Who is the learner? Who is responsible for delivery of instruction? And where does the instruction take place? This finding is consistent with earlier studies on this subject. Fuchs, Fuchs, Hamlett and Ferguson (1992) observed that when teachers adapted their instructional programmes to their pupils' educational needs, the students invariably learnt more.

Taken as a whole, the variables 'student characteristics' and 'out-of-school' contextual factors account for a modest percentage $(11.8 \%)$ of teachers' perceptions about the academic attainment of students with special educational needs. The types of cause evoked by teachers include prior knowledge about students' academic profile, academic motivation styles, affective factors and family atmosphere.

As expected, data analysis of teachers' perceptions of the causes of student academic failure shows that the latter is primarily attributed to external factors. Comparing causes that explain students' academic success or failure reveals a significant change in the nature of teachers' beliefs. For instance, the 'school climate' aspect emerges as the primary explanation for pupils' academic failure (40\%), whereas an analysis of the factors that contribute to successful academic performance shows that 'school climate' decreases its importance and is only mentioned by $21.3 \%$ of respondents. Similarly, 'out-of-school' contextual variables play a significant part in teachers' understanding of the causes of students' academic outcomes while the causes of failure are seen as being largely under the control of school administrators.

However, the most unexpected result was the lesser degree of importance attached to 'curriculum design'. Teachers' beliefs regarding this domain are consistent with some of the common dilemmas that teachers meet when discussing curricular adaptations (Udvari-Solner, 1996). Among the most common constraints, teachers reported the lack of a shared language in which to discuss curricular adaptation and overcoming barriers in curriculum planning. As a result, curricular goals, lessons and activities are frequently not adjusted to students' academic needs.

\section{Implications for practice}

This study provided evidence of variables that explain support teachers' beliefs concerning the academic achievement of students with special educational needs. Teachers identified 'teaching approach' and 'curriculum design' as key components in students' academic success. Although greater emphasis is being placed on these issues, a wide range of teachers do not receive initial training on how to teach students with special educational needs and consequently may not feel confident of the knowledge and skills they need to plan adaptations intended to accommodate these pupils. In fact, teacher training programmes do not provide sufficient coursework and field experience to enable teachers to support students with special educational needs in classrooms. In addition, a review of the literature on instructional adaptations by Scott, Vitale and Masten (1998) showed that teachers have to deal with several types of difficulty when they come to adapt teaching methods and that the specific differentiated adaptations designed to respond to the needs of students with special educational needs are not actually implemented.

Moreover, studies that address instructional adaptations also show that educators tend to analyse their teaching performance in relation to the current knowledge about effective teaching practices and thus discover that there may be significant differences between the theoretical frameworks and what actually happens in classrooms. Such findings indicate that the availability of differentiated instruction techniques is less important than the comfort levels that teachers feel when using them (King-Sears \& Cummings, 1996).

The classroom that includes students with special educational needs presents a complex and challenging environment. Research is needed to identify and characterise effective instructional practices for these students and to ascertain how, with whom, where and when these practices are provided most effectively. Inasmuch as student performance is determined in large measure by environmental and teacher-related variables, further research should focus on educational settings in which all students fully participate in classroom routines, regardless of any special educational needs.

The results in relation to 'school climate' reveal that collaboration between teachers is another notable element in a successful learning environment. Although research on classroom teachers' acceptance of intervention strategies (for example, Giangreco, Dennis, Cloninger, Edelman \& Schattman, 1993) has shown that the type of assistance received from educational support personnel may be intrusive and disruptive, participants in this study emphasise positive relationships between support and regular teachers. Complementing this finding, research has also revealed that limited school support functions as a substantive barrier to the accommodation of students' learning needs (Scott, Vitale \& Masten, 1998).

Finally, teachers described positive working interactions as a key element in successful planning and curricular adaptations. In broad terms, teachers consider co-operation among themselves as both a way of overcoming problems associated with professional isolation and as an essential strategy for increasing their professional repertoire. 


\section{References}

Ainscow, M. (1997) 'Towards inclusive schooling', British Journal of Special Education, 24 (1), 3-6.

Aloia, G. F., Maxwell, J. A. \& Aloia, S. D. (1981) 'Influence of a child's race and the EMR label on the initial impressions of regular classroom teachers', American Journal of Mental Deficiency, 85 (4), 619-623.

Anderson, C. S. (1985) 'The investigation of school climate', in G. R. Austin \& H. Garber (eds) Research on Exemplary Schools. New York: Academic Press.

Bender, W. N., Vail, C. O. \& Scott, K. (1995) 'Teachers' attitudes toward increased mainstreaming: implementing effective instruction for students with learning disabilities', Journal of Learning Disabilities, 28 (2), 87-94.

Berliner, D. C. (1985) 'Effective classroom teaching: the necessary but not sufficient condition for developing exemplary schools', in G. R. Austin \& H. Garber (eds), Research on Exemplary Schools. New York: Academic Press.

Bogdan, R. \& Biklen, D. (1983) Qualitative Research for Education: an introduction to theory and methods. Boston: Allyn and Bacon.

Booth, T., Ainscow, M. \& Dyson, A. (1997) 'Understanding inclusion and exclusion in the English competitive education system', International Journal of Inclusive Education, 1 (4), 337-355.

Center, Y. \& Ward, J. (1987) 'Teachers' attitudes towards the integration of disabled children into regular classes', Exceptional Children, 34 (1), 1-16.

Chalmers, L. (1991) 'Classroom modification for mainstreamed students with mild handicaps', Intervention in School and Clinic, 27 (1), 40-42.

Cooper, H. \& Burger, J. (1980) 'How teachers explain students' academic performance: a categorization of free response academic attributions', American Journal of Educational Research, 17, 95-109.

Englert, C. S., Tarrant, K. L. \& Mariage, T. V. (1992) 'Defining and redefining instructional practice in special education: perspectives on good teaching', Teacher Education and Special Education, 15 (2), 62-86.

Fuchs, L. S., Fuchs, D., Hamlett, C. L. \& Ferguson, C. (1992) 'Effects of expert system consultation within curriculum-based measurement using a reading maze task', Exceptional Children, 58, 436-450.

Fullan, M. G. \& Miles, M. B. (1992) 'Getting reform right: what works and what doesn't', PHI DELTA KAPPAN, 73 (10), 745-752.

Gartner, A. \& Lipsky, D. K. (1987) 'Beyond special education: toward a quality system for all students', Harvard Educational Review, 57 (4), 367-395.

Giangreco, M., Dennis, R., Cloninger, C., Edelman, S. \& Schattman, R. (1993) “'I've counted Jon": transformational experiences of teachers educating students with disabilities', Exceptional Children, 59, 359-372.

Good, T. (1981) 'Teacher expectations and student perceptions: a decade of research', Educational Leadership, 38, 415-422.

Graham, S. (1991) 'A review of attribution theory in educational contexts', Educational Psychology Review, 3, 5-39.
Jamieson, J. D. (1984) 'Attitudes of educators toward the handicapped', in R. L. Jones (ed.) Attitudes and Attitude Change in Special Education: theory and practice. Reston, VA: The Council for Exceptional Children.

Johnson, D. W. \& Johnson, R. T. (1994) Learning: Together and Alone: cooperative, competitive, and individualistic learning (fourth edition). Boston: Allyn \& Bacon.

Kauffman, J. M., Lloyd, J. W. \& McGee, K. A. (1989) 'Adaptive and maladaptive behavior: teachers' attitudes and their technical assistance needs', The Journal of Special Education, 23, 185-200.

King-Sears, M. E. \& Cummings, C. (1996) 'Inclusive practices of classrooms teachers', Remedial and Special Education, 17, 217-225.

Nevin, A. (1993) 'Curricular and instructional adaptations for including students with disabilities in cooperative groups', in J. Putman (ed.) Cooperative Learning and Strategies for Inclusion: celebrating diversity in the classroom. Baltimore, MA: Paul H. Brookes.

Olson, M., Chalmers, L. \& Hoover, J. (1997) 'Attitudes and attributes of general education teachers identified as effective inclusionists', Remedial and Special Education, 18, 29-35.

Pugach, M. C. \& Johnson, J. L. (1994) Collaborative Practitioners, Collaborative Schools. Denver: Love Publishing Co.

Rainforth, B. \& England, J. (1997) 'Collaboration for inclusion', Education and Treatment of Children, 20 (1), 85-105.

Reynolds, D. (1990) 'Changing ineffective schools', in M. Ainscow (ed.) Effective Schools for All. London: David Fulton Publishers.

Rolinson, M. \& Medway, F. (1985) 'Teachers' expectations and attributions for student achievement: effects of label, performance pattern, and special education intervention', American Educational Research Journal, 22, 561-573.

Scott, B., Vitale, M. \& Masten, W. (1998) 'Implementing instructional adaptations for students with disabilities in inclusive classrooms: a literature review', Remedial and Special Education, 19 (2), 106-119.

Scruggs, T. E. \& Mastropieri, M. A. (1996) 'Teacher perceptions of mainstreaming/inclusion, 1958-1995: a research synthesis', Exceptional Children, 63 (1), 59-74.

Semmel, M., Abernathy, T., Butera, G. \& Lesar, S. (1991) 'Teacher perceptions of the Regular Education Initiative', Exceptional Children, 58, 9-24.

Skrtic, T., Sailor, W. \& Gee, K. (1996) 'Voice, collaboration, and inclusion: democratic themes in educational and social reform initiatives', Remedial and Special Education, 17, 142-157.

Slee, R. (1990) 'Learning initiatives to include all students in regular classrooms', in M. Ainscow (ed.) Effective Schools for All. London: David Fulton Publishers.

Soodak, L. C., Podell, D. M. \& Lehman, L. R. (1998) 'Teacher, student, and school attributes as predictors of teachers' responses to inclusion', The Journal of Special Education, 31, 480-497. 
Udvari-Solner, A. (1996) 'Examining teacher thinking: constructing a process to design curricular adaptations', Remedial and Special Education, 17 (4), $245-254$

Udvari-Solner, A. \& Thousand, J. (1995) 'Effective organizational, instructional and curricular practices in inclusive schools and classrooms', in C. Clark, A. Dyson \& A. Millward (eds) Towards Inclusive Schools? London: David Fulton Publishers.

Villa, R. A., Thousand, J. S., Meyers, H. \& Nevin, A. (1996) 'Teacher and administrator perceptions of heterogeneous education', Exceptional Children, 63 (1), 29-45.

Wang, M. C., Haertl, G. D. \& Walberg, H. J. (1993)

'Toward a knowledge base for school learning', Review of Educational Research, 63 (3), 249-294.
Weber, R. P. (1990) Content Analysis. Newbury Park, CA: Sage Publications.

Welch, M. (1989) 'A cultural perspective and the second wave of educational reform', Journal of Learning Disabilities, 22, 537-540.

Address for correspondence

Dr José Castro Silva

Rua Jardim do Tabaco, 34

1149 - 041 Lisboa

Portugal

Email: jcsilva@ispa.pt

Manuscript submitted: July 2002 Accepted for publication: November 2003

\section{Introducing an} exciting, inspirational new partnership Schools Pledge givers all mainstream schooks in the UX the opportunity to adopt a positive attitude fowarchs desfness.

trou wok in primary or seoondery schod and wadd then so proviniso a died trondy srinormort. to FAEE Deo Frindly Strockt Pledpo pasker epport you in your work whi AL the dhaten in your school. Ereure fret the whobe of your eathod comrurily is thed wwors try emaing deaffriendlypledgeondek arguk or by esilne 02070141115 and requeting a pank.

For more irlormason about the Netiond Ded Chidrevis Sodiety pleses wet ar websle erww.nden.erguk, or errel helplinetinden. orguk

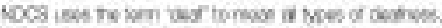

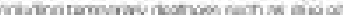

NDCS Kktt

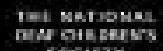
seciev

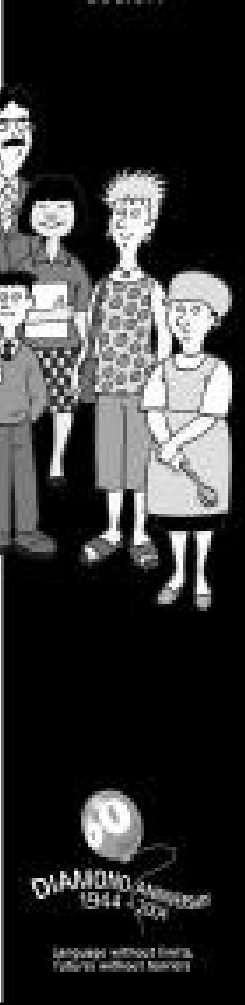

MASEN

and



Launched on October 22nd, this new partnership between NASEN and David Fulton Publishers will ensure that NASEN continues to provide high quality books and resources written by experts in the field of SEN.

For more details of special offers, NASEN member discounts and new titles, visit the NASEN website www.nasen.org.uk or shop on-line at www.onestopeducation.co.uk 